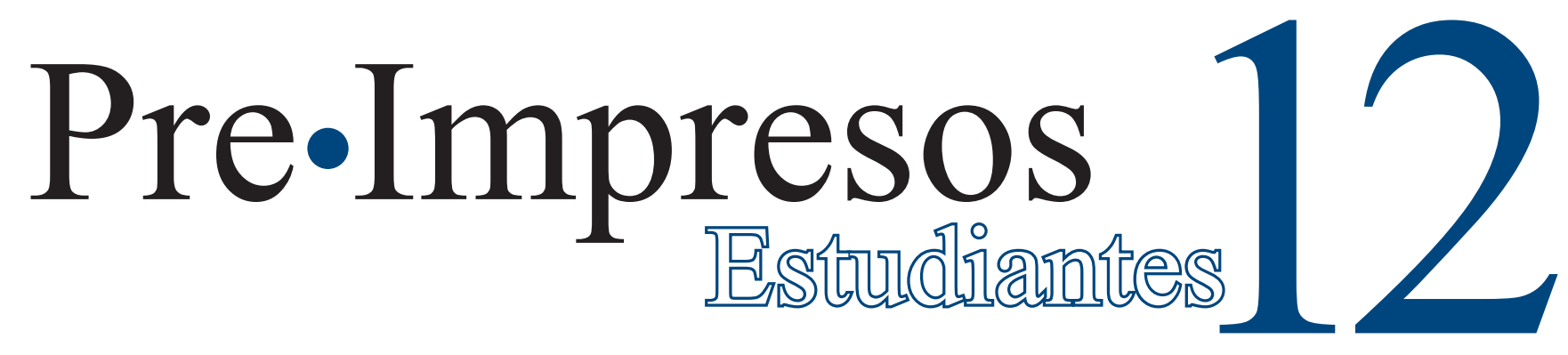

Facultad de Ciencia y Tecnología Departamento de Física - 2017-I • ISSN-E: 2323-0193 - ISSN 2539-0945

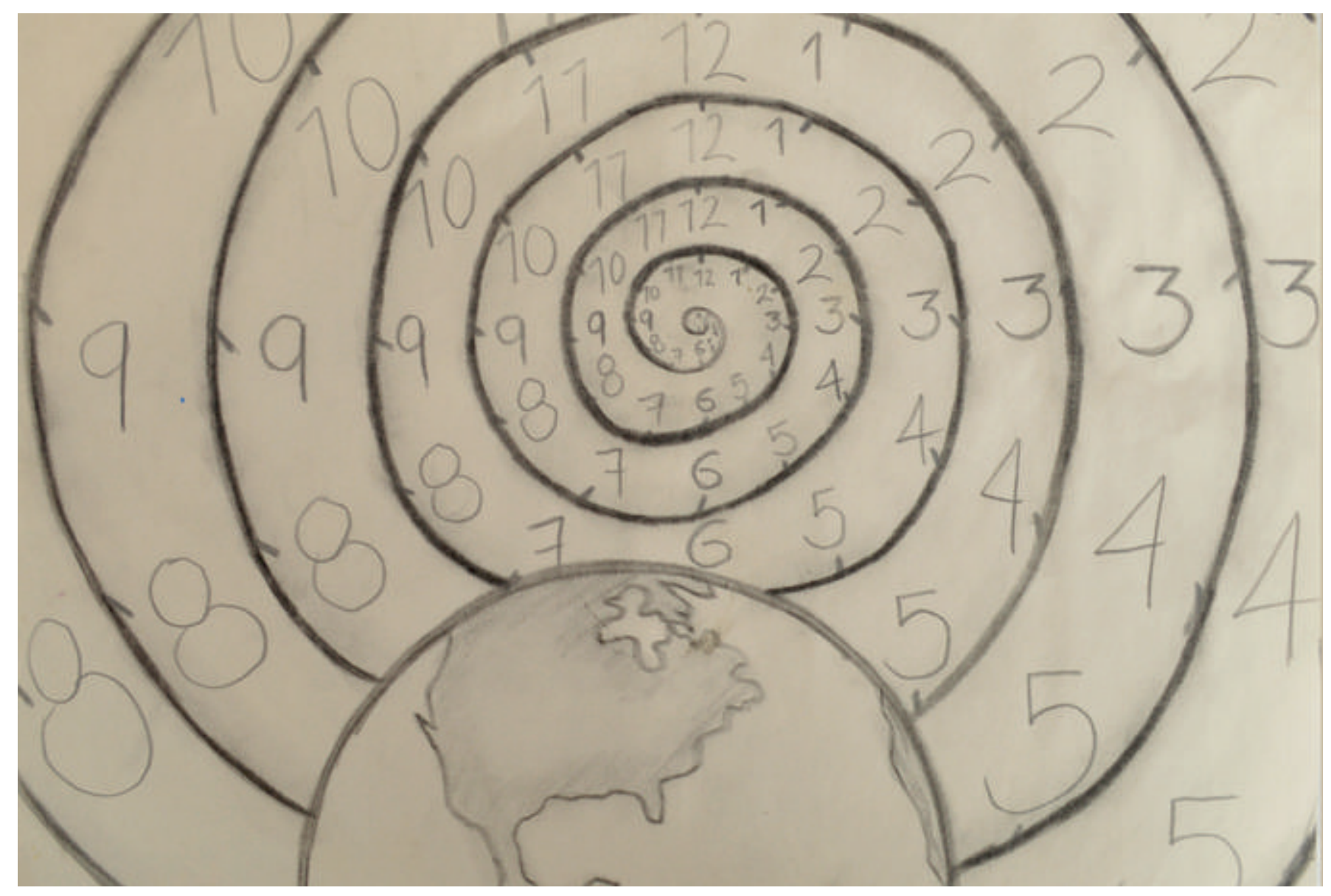

Las perspectivas espaciotemporales en grado séptimo

Sebastián Guayara 


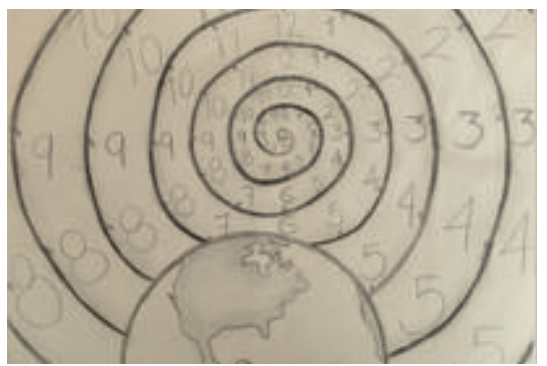

\section{Pre·Impresos 12}

Adolfo León Atehortúa Cruz Rector

Mauricio Bautista Ballén Vicerrector Académico

Sandra Patricia Rodríguez Ávila Vicerrectora de Gestión Universitaria

Fernando Méndez Díaz Vicerrector Administrativo y Financiero

Helberth Augusto Choachí González Secretario General

Facultad de Ciencia y Tecnología Departamento de Física

Steiner Valencia Vargas Director Departamento

Sandra Milena Forero Díaz Coordinadora Licenciatura en Física

Juan Carlos Orozco Cruz Supervisión de contenido

Juan Carlos Bustos Gómez Director de la revista

Samuel Eduardo Sediles Martínez Coordinador de la revista

(C) Universidad Pedagógica Nacional (C) Sebastián Guayara

Silvia Cabrales

Portada

Artículos publicados en diferentes medios escritos y referenciados en cada uno de los textos.

ISSN-E: 2323-0193

ISSN: 2539-0945

Diseño y Preparación editorial Universidad Pedagógica Nacional Grupo Interno de Trabajo Editorial 2018

Alba Lucía Bernal Cerquera

Coordinadora Grupo Interno de Trabajo Editorial

Viviana Vásquez

Editora de Revistas

Impreso por Javegraf

Bogotá, Colombia

\section{Las perspectivas espaciotemporales en grado séptimo}

Las perspectivas espaciotemporales en grado séptimo

Resumen

Abstract

Introducción

Un día como hoy

Un día en 1900

Relativamente séptimo

Reflexiones

Referencias

Anexos

Eventos de la Facultad

Jornada del Educador Matemático

Acerca de la serie Pre-impresos

\section{Presentación}

La serie Pre.Impresos Estudiantes es una iniciativa editorial del Proyecto Comunicación y Publicaciones de la Facultad de Ciencia y Tecnología (FCT), cuya idea central es trabajar por la cualificación de la escritura, para dar visibilidad a la producción intelectual de los maestros en formación y en ejercicio. Con esta publicación se busca tender puentes entre los saberes especializados y la cultura en general, además de contribuir al fortalecimiento de la docencia y la investigación en educación.

Asimismo, constituye una estrategia de comunicación que posibilita la circulación adecuada de información y promueve la reflexión sobre temas y actividades inherentes a las ciencias, la matemática, la tecnología y su enseñanza. Con ella también se espera favorecer la integración de los equipos de trabajo y la construcción de relaciones de cooperación entre los diferentes miembros de la comunidad académica de la Facultad.

Estos aspectos, relacionados con los fines misionales de la Universidad Pedagógica Nacional, resultan pertinentes y significativos en la formación de nuevas generaciones de maestros e investigadores en pedagogía, que en su futura práctica profesional afrontarán diversos retos y circunstancias que el entorno social del país le plantea a la educación.

\section{Información:}

pre_impresos@pedagogica.edu.co Facultad de Ciencia y Tecnología

Teléfonos: (57) (1) 3471190 / 5941894 Ext. 242 


\title{
Las perspectivas espaciotemporales en grado séptimo
}

\author{
Sebastián Guayara \\ Correo: dsguayaram@gmail.com \\ Universidad Pedagógica Nacional
}

\section{Resumen}

La experiencia que se presenta en este trabajo tiene como objetivo examinar la concepción de espacio y tiempo de los estudiantes de grado séptimo del colegio Tomás Cipriano de Mosquera, para indagar si sus ideas son cercanas a los conceptos establecidos por la física moderna. Se decidió trabajar con esta población, porque no había tenido contacto con los temas de la asignatura de física y, por tanto, tiene una visión menos contaminada del tema. La propuesta de aula se desarrolló en la clase de matemáticas ya que en su plan de estudios no existe la asignatura de física y la clase de ciencias tiene un enfoque biológico. Durante su realización se observó un mayor interés en la clase, pues los chicos participaron activamente con preguntas que, como ellos lo manifestaban, nadie les había respondido, además algunos indagaron por su cuenta sobre los viajes en el tiempo, sobre Einstein e incluso hicieron circular historias que afirmaban que él estaba en el futuro, por lo cual fue necesaria la continua dirección del docente en la investigación para mantener el enfoque y proponer retos pedagógicos acordes a los temas abordados. Asimismo, se concluyó que los estudiantes tienen una perspectiva del espacio y del tiempo dependiente del contexto de cada uno, los programas de televisión, libros y comics muestran una concepción muy cercana a la física moderna y, por tanto, los chicos están mucho más cercanos de lo que pensábamos los docentes a la concepción de la física moderna del espacio y el tiempo. En general, estos conceptos pasan desapercibidos por parecer muy sencillos, pero no resultan tan simples de definir y no siempre son tan claros para el maestro. Ahora bien, si los jóvenes no están en condiciones de comprenderlos por ser conceptos tan complejos, ¿no resultaría más cómodo dejar la discusión en el tintero?

\section{Palabras clave:}

Tiempo, espacio, enseñanza de la física, física moderna 


\section{Abstract}

The experience presented in this summary aims to examine the conception of space and time of seventh grade students of Tomas Cipriano De Mosquera School, in order to investigate whether their ideas are close to the concepts established by Modern physics. It was decided to work with this population because it had not had contact with the subjects of physics course and therefore has a less polluted vision of the subject. The classroom proposal was developed in the mathematics class because in its curriculum there is no physics subject and the science class has a biological focus. During its realization there was a greater interest in the class, as the students participated actively with questions that, as they manifested, no one had answered them, besides some of them inquired on their own about time travel, Einstein, and even circulated stories that claimed that he was in the future so it was necessary the continuous teaching direction in the research to maintain the focus and propose pedagogical challenges in line with the topics addressed. It was also concluded that students have a perspective of space and time dependent on their context; television programs, books and comics show a conception very close to modern physics and therefore, students are much more close to what teachers think to the conception of modern physics of space and time. In general, these concepts go unnoticed to seem very simple, but they are not so simple to define and are not always so clear for teachers. Now, if young people are not able to understand them because they are such complex concepts, wouldn't it be easier to leave the discussion open?

Keywords:

Time, space, physics teaching, modern physic

\section{Introducción}

El artículo presentado a ustedes es derivado del trabajo de grado que realicé para obtener el título de licenciado en Física: "La enseñanza de la TER: reglas fijas y relojes con estudiantes de grado séptimo". Al inicio, este trabajo estaba enfocado en analizar las consecuencias filosóficas de la teoría de la relatividad, pero decidí acotarlo, al ser un tema tan extenso. En este punto fue decisiva la sugerencia de mi asesor, profesor Juan Carlos Orozco: leer minuciosamente los textos originales de Einstein y de otros científicos para mirar las soluciones que dieron a ciertas problemáticas y realizar una contextualización que mejorara la comprensión en la actualidad de dichos conocimientos. Este enfoque se denomina estudios histórico-críticos y para el presente caso permitió examinar la perspectiva de los autores de las teorías sin mediadores teóricos. El análisis evidenció que uno de los más preocupados por la comprensión de su teoría era el mismo Einstein, quien publicó libros en compañía de científicos de su época, en los que utilizaba ejemplos cotidianos, sencillos y comprensibles para la mayoría de las personas, sin necesidad de que fueran físicos o científicos.

La idea de que la física moderna no puede ser enseñada en los colegios porque es muy compleja y que es más fácil que los estudiantes aprendan física clásica es rebatible, pues los chicos hoy día interactúan frecuentemente con nociones desarrolladas gracias a la revolución científica, originada por la física moderna. A diario consumen programas, películas y libros que los ponen en contacto con ideas de viajes en el tiempo, objetos enormes y minúsculos, etc., tal como lo muestra la gráfica de la portada de esta edición, que representa la unión del espacio-tiempo, elaborada por una de las estudiantes que participaron en la experiencia narrada en este artículo.

La complejidad de los temas, concluye la investigación, depende de la estrategia utilizada para aproximar a los estudiantes a los 
conceptos; concebidos estos como un paso necesario para una posterior formalización con ayuda de la matemática. Por ello, se decidió que la primera actividad de la propuesta de aula que aquí se presenta debía consistir en indagar la percepción de los estudiantes sobre el espacio y el tiempo por medio de una representación gráfica - la cual, en general, arrojó como resultado una percepción cercana a la propuesta de Einstein-. Luego, se eligió un material audiovisual muy sencillo y divertido que mostrara los conceptos de espacio y tiempo, la película infantil Alicia a través del espejo, con la cual se desarrolló otra actividad que planteaba a los estudiantes la posibilidad de elegir un final para la película, según su percepción, como si fueran directores de cine.

Posteriormente, llegó la fase más difícil: las actividades para evidenciar el espacio como una relación de cuerpos constatable con la medición de objetos, experiencia que, por lo general, pasa desapercibida, pues el espacio se asume como algo lejano que está fuera de la atmósfera. Dado el interés de los chicos, que desencadenó muchas preguntas, se decidió proyectar una segunda película, en este caso Interestellar, que les resultó aún más interesante que la anterior. Los impactó en especial la idea de que podríamos llegar a tener un planeta desierto; se cuestionaron sobre los viajes en el tiempo y sobre cosas que siempre habían escuchado, pero que no habían entendido, tales como los agujeros negros o agujeros de gusano, explicados en la película con sencillez abrumadora. Después de realizadas las actividades y discusiones, culminamos nuestra experiencia de aula retomando las ideas de los estudiantes para obtener resultados y conclusiones.

La estructura del texto es relativista, porque se plantea un juego con los marcos de referencia en tono narrativo, para mirar diferentes perspectivas del fenómeno. En la primera parte se explora la perspectiva del docente, pensando su papel como investigador y encargado de contextualizar el conocimiento en el aula; en la segunda parte se muestran las situaciones problemáticas abordadas por Einstein en 1905, las cuales dieron origen a la teoría especial de la relatividad (TER), y, por último, aunque no menos importante, se muestra la forma como se percibió el trabajo desde la perspectiva del estudiante, que es la razón de ser de esta propuesta. Estas tres perspectivas nos permiten realizar una lectura más acertada de la realidad, sin privilegiar el punto de vista de algún observador en particular; esta es una idea fundamental de la TER que desvirtúa la percepción muy difundida de que la relatividad demostró que no existe una verdad y que todo es relativo. Es una mejor interpretación pensar que hay varias formas de ver una misma cosa.

\section{Un día como hoy}

Estamos en un mundo cambiante, activo las 24 horas del día, en el que se deben hacer las cosas cada vez mejor y más rápido; contexto que plantea a los docentes la exigencia de buscar mejores formas de llevar los conocimientos a los estudiantes, de tomar en cuenta su entorno y diario vivir, no solo en física, sino en todas las asignaturas y ámbitos de la vida escolar.

Algo cotidiano para muchos estudiantes es la televisión y por supuesto los dibujos animados, como, por ejemplo, Dragon Ball $Z$, serie en la que, a mi juicio, existe un momento fantástico, cuando Gokú, uno de los personajes, realiza la teletransportación. Es casi delirante pensar en esta posibilidad, ya que esto haría las cosas más sencillas. Si el plan familiar del fin de semana fuera ir a Cartagena en carro, habría que levantarse temprano y prepararse para una travesía de al menos 18 horas, partiendo de Bogotá; pero, si hubiera un Gokú en la familia todo cambiaría, pues él haría uso de la teletransportación y en un santiamén estaríamos en Cartagena disfrutando del sol, la playa, la brisa y el mar. Quizá ustedes también hayan imaginado tan maravilloso cuadro, pero esto solo es posible en los dibujos animados e irrealizable en la vida real. 


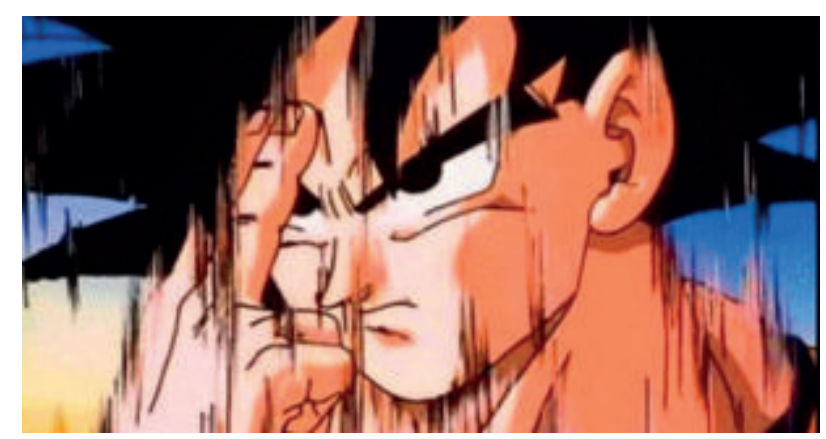

Ilustración 1. Goku realizando la teletransportación Fuente: La Red (2017).

Supongamos que la teletransportación es posible, que podemos recorrer grandes distancias en tiempos muy cortos, como ir de Bogotá a Cartagena en 2 segundos o menos. Resulta interesante, aunque la idea no es nueva, pues películas, libros, cómics y dibujos animados la presentan a diario.

La teoría de la relatividad especial, grosso modo, dice que entre más cercano a la velocidad de la luz se mueva un cuerpo, menos tiempo le tomará recorrer iguales distancias. Expliquémoslo un poco.

Hemos escuchado siempre una expresión coloquial: "Póngase en los zapatos del otro", esto implica que no todos tenemos la misma perspectiva de la realidad; mientras una persona que ve un lápiz de frente dirá que observa un círculo, otra persona que lo observa de lado verá un pentágono con sus paralelas muy largas. En este punto, no podemos decir quién tiene la razón, aunque el lápiz no deja de serlo, independientemente de la forma en la que cada observador lo ve. Claramente, llegamos al consenso de que no es posible determinar cuál de los observadores tiene la razón, por tanto, solo plantearemos que son visiones diferentes de un objeto o fenómeno. Es esta la invitación que nos hace la física relativista: no privilegiar unos marcos de referencia sobre otros, más bien considerarlos igualmente válidos.
Lo anterior nos permite plantear que dos personas pueden ser gemelas, por ejemplo, y no tener gustos semejantes. Extendiéndolo a nuestra explicación, una persona que viaja a grandes velocidades - cercanas a la velocidad de la luz - y una que viaja a bajas velocidades — velocidades cotidianas, incluso en un Audiexperimentarán sensaciones diferentes. Suena coherente, ¿no? Imaginemos que vamos en una nave tan rápida que aún no ha sido construida y vamos a hacer un viaje por nuestro sistema solar. Si nos movemos a la mitad de la velocidad de la luz durante un segundo, en nuestra nave registraremos un lapso de un segundo, como es de esperar $y$, aunque parezca extraño, para una persona que se encuentra aquí en la Tierra pasaría 1,414 segundos ¿cómo es posible esto? Aún más sorprendente es pensar que si nos movemos a 0,99 de la velocidad de la luz, es decir, muy cerca de los 300000 km/s, mientras registramos un tiempo de un segundo a bordo de nuestra nave, en la Tierra se medirían 10 segundos. De nuevo, ¿es esto posible? Suena descabellado, pero interesante, ¿no? La situación expuesta anteriormente se denomina paradoja de los gemelos, y según la TER es realizable, solo debemos idear la forma de viajar a altas velocidades, ese es el reto.

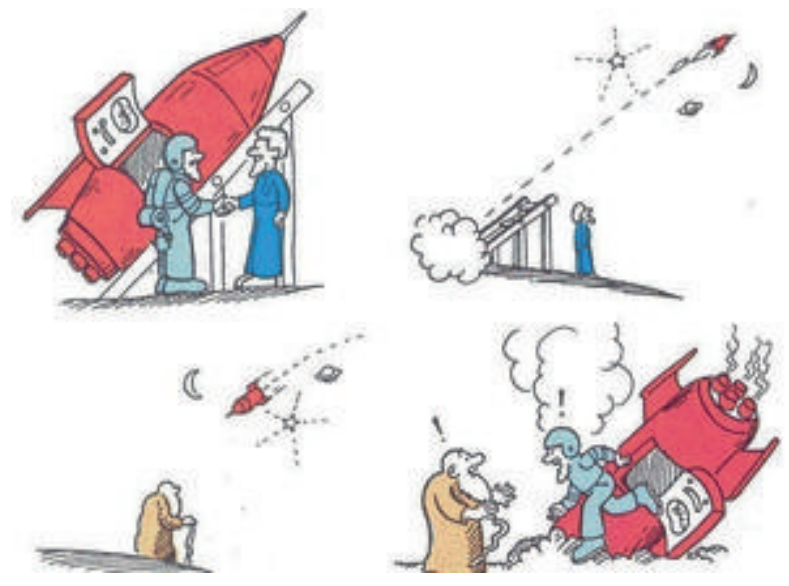

Ilustración 2. Paradoja de los gemelos Fuente: La Bioguia (2017). 
En la película Interestellar, se muestra una situación que parece obra de la ciencia ficción. El padre aborda la nave con 37 años y la hija tiene cerca de 15; para él, que viaja a grandes velocidades, han pasado apenas unos meses; su hija le envía un vídeo en el cual dice que ya tiene su misma edad y aún lo espera. El final de la película es complejo e impactante pues la hija muere de vieja y él todavía es joven.

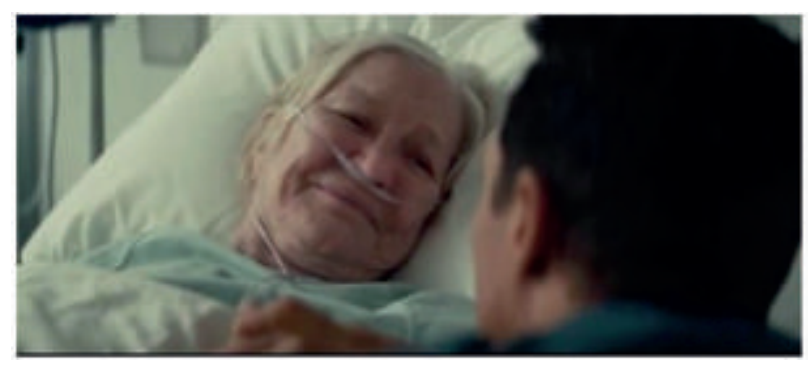

Ilustración 3. Padre e hija luego de viaje en el tiempo Fuente: Youtube (2015).

Como docente e investigador solo añadiré lo interesante y fructífero que fue llevar estos contenidos al aula y asumir al estudiante como parte activa en el proceso de generación de conocimiento.

La física es una materia que en el sistema educativo colombiano se ve en la mayoría de colegios en grados 10 y 11 , pero debido a que los proyectos educativos institucionales no tienen un enfoque científico, el país se queda corto con relación a países de habla hispana, aunque con la Ley 115 de 1994 se pretendió zanjar la brecha tecnológica y educativa. Los estándares, que son básicamente la apuesta que se hizo hace más de 20 años a nivel educativo, fijan el rumbo de las asignaturas y los mínimos requeridos en la enseñanza. En el documento, se sustenta que la concepción de ciencia que lo orientó fue una perspectiva científica cambiante y no finalizada (Ministerio de Educación Nacional, MEN, 2006), sin embargo, los estándares tienen más de 20 años y no se han modificado, lo que resulta sumamente contradictorio. Algo semejante a lo acontecido con el presupuesto del presente año (2017) para la ciencia, que se redujo en un $41 \%$ para el rubro de funcionamiento, en relación con el año anterior. No obstante, según fuentes oficiales, la ciencia constituye una de las locomotoras del actual Gobierno. En este sentido, es tarea de los docentes como investigadores ayudar a plantear las necesidades que la educación el siglo XXI exige, para tener mejores conocimientos que permitan comprender un mundo cada vez más globalizado.

La experiencia de aula que se realizó con los chicos de séptimo grado arrojó resultados interesantes en cosas simples de observar, como la actitud frente a la clase. Por ejemplo, un día, durante la proyección de Interestelar sonó el timbre que indicaba el descanso, pero aún no había terminado la película y los chicos decidieron continuar viéndola. Después de que finalizó, mientras se resolvían dudas, se pasó casi todo el descanso, lo que a mi juicio demuestra el interés de los chicos por el tema. Fue realmente gratificante.

La portada de la presente edición es un dibujo que representa la unión de lo que concebimos como el espacio (la Tierra y sus alrededores) y el tiempo como un bucle del cual no podemos salir, y al que no podemos ser ajenos, pero que los físicos de principios del siglo XX no comprendieron de esa manera o no tuvieron la suspicacia que le sobró a Einstein en ese momento para representar estos conceptos en una cuarta dimensión. 


\section{Un día en 1900}

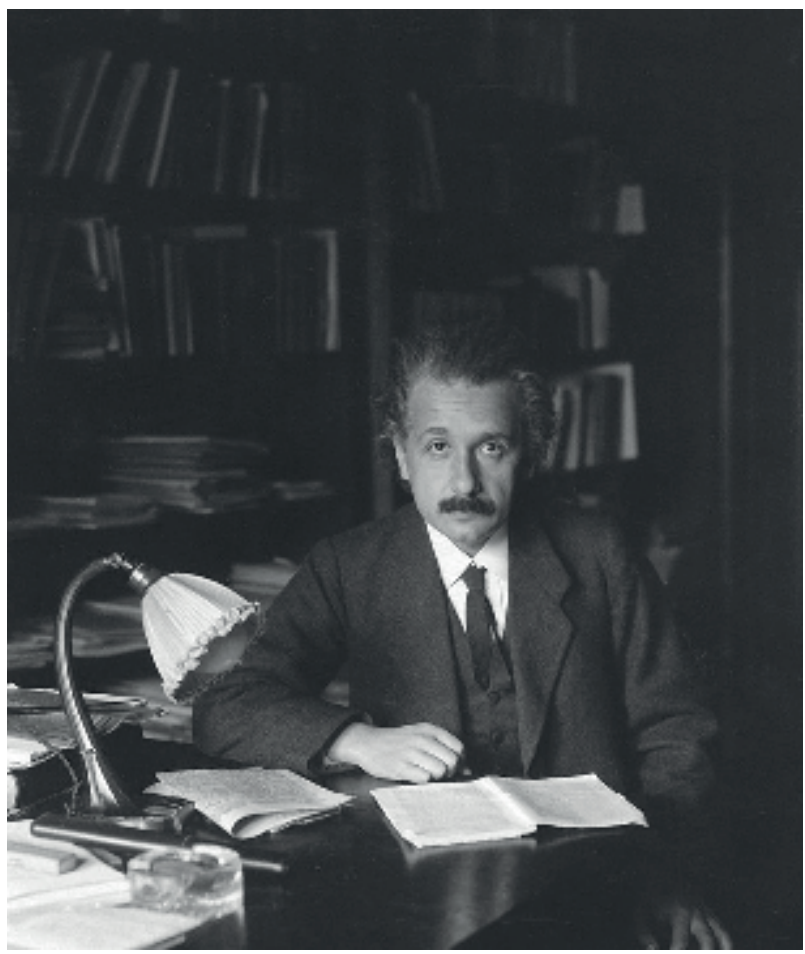

Ilustración 4. Einstein absorto en sus cavilaciones. Fuente: “Albert Einstein" en Wikipedia (2017)

Hagamos un viaje en el tiempo a inicios del siglo $\mathrm{XX}$, cuando la física era una ciencia con unos fuertes cimientos, labrados durante más de 300 años por científicos excepcionales como Galileo, Copérnico, Newton, Faraday y Maxwell, que marcaron su historia. Nuestro viaje empezará en Berna, Suiza, en una oficina de patentes. Allí encontramos a Albert Einstein un físico que, como sabemos, en el futuro será reconocido como una de las mentes más brillantes de la humanidad. En este momento, es un día normal de trabajo, él como siempre algo despelucado y un tanto absorto en sus cavilaciones. No le cabía un pensamiento más en la cabeza, después de terminar de leer las agudas críticas de Mach a la física newtoniana y los minuciosos análisis de Poincaré, que obtuvo resultados cercanos a la TER que posteriormente desarrolló Einstein.
En este momento -inicios del siglo $x x$ - los trenes son el motor del desarrollo de Europa, algo que deberíamos recordar en el siglo XXI. Este medio de transporte de mercancías y viajeros es vital no solo para la economía, sino también para la física. Einstein pierde el hilo de sus pensamientos debido a un zancudo que acaba de zumbar en su oído y que lo saca de su reflexión, pero lo lleva a hacer una conjetura muy interesante sobre la relación que hay entre la posición del zancudo, que quiere pasar a mejor vida, y cuánto se acerca este a la pared para lograr su objetivo. Él lo describe así:

Cuando queremos describir el movimiento de un punto material, especificamos los valores de sus coordenadas en función del tiempo. Ahora bien: debemos tener muy presente que una descripción matemática de esta especie no tiene significado físico alguno, a menos que tengamos las ideas muy claras acerca de qué es lo que entendemos por "tiempo". (Einstein e Infeld, 1939, p. 36).

El zancudo se le escapa a nuestro científico, pues no es un cazador experto, de nuevo, el ruido del tren que llega a la estación cercana a su oficina da rienda suelta a su sin igual imaginación en la cual la simplicidad se hace latente, algo que solo logran las mentes brillantes.

Por ejemplo, si yo digo: “Ese tren llega a las siete", lo que intento decir es algo así como: "La posición de la manecilla pequeña de mi reloj en las siete y la llegada del tren son sucesos simultáneos" [...]. Podría parecer que para superar todas las dificultades en torno a la definición de "tiempo" bastaría con sustituir"la posición de la manecilla pequeña de mi reloj" por "tiempo". Y, efectivamente, tal definición es satisfactoria cuando lo que interesa es definir el tiempo únicamente para aquel lugar donde está situado el reloj. (Einstein et al., 1993, p. 63).

Para Einstein, el tiempo no es más que el reloj que mide el cambio de la posición inicial de un cuerpo con relación a la posición final del mismo cuerpo. Lo habían dicho Poincaré y Galileo, los experimentos solo nos dan relaciones 
entre cuerpos ${ }^{1}$ y no entre los cuerpos y absolutos que son externos al sistema experimental dispuesto. Por ello, no se puede hablar de un tiempo absoluto si solo se miden cambios de posición de los cuerpos en la Tierra, pues la Tierra no es un marco absoluto de medición.

Einstein tiene una reunión a las 9:00 a. m. con su jefe y a las 10:00 a. m. debe tomar el tren a Zúrich; pero, ¿por qué siempre suponemos que el otro tiene la misma hora que nuestro reloj? En el siglo del que venimos, los relojes se sincronizan satelitalmente, pero a inicios del siglo $\mathrm{XX}$ la tarea no es tan simple.

Einstein imagina la siguiente situación: un tren sale a las 3:00:00 de Berlín y va hacia Moscú, a donde, según los cálculos del maquinista, llegará a las 5:30:00. En una provincia cercana a Moscú, hay un guardagujas que tiene la labor de cambiar la dirección de las vías del tren a las 5:28:00. El resultado sería catastrófico si el guardagujas no tuviera sincronizado su reloj con la estación de partida; pero, ¿cómo evitar un desastre? Hay dos opciones para realizar la sincronización:

Una opción sería elegir un reloj central y a una hora determinada, las 3:00:00, enviar un rayo luminoso a la otra estación, cuando llegue el rayo de luz a la estación se actualizará la hora a las 3:00:00 y así realizaríamos la sincronización, ¿no hay nada raro en esta sincronización? Para Einstein sí lo hay, pues aunque la luz viaja muy rápido, tiene un tiempo de desplazamiento y si sale un rayo a las 3:00:00 de la estación central, llegará por ejemplo a las 3:00:02 a otra estación y esto debe tenerse en cuenta o el resultado sería desastroso.

La solución que propone Einstein a este problema es sencilla. La luz, al tener una velocidad absoluta independiente del estado de movimiento, se moverá la misma cantidad de espacio por cada segundo que recorra. Podemos tener, entonces, un reloj central en Berlín y cuando llegue a la estación de Moscú el pulso debe retornar, de manera que cuando regrese de nuevo a Berlín,

1 La traducción se realizó a partir del original en inglés por parte de María Cecilia Gramajo, Clara Inés Chaparro y Juan Carlos Orozco en el marco del seminario tópicos de Mecánica clásica de la maestría de docencia de la física de la Universidad Pedagógica Nacional se debe dividir en dos el tiempo que tardó en ir y volver y ello nos dará la anhelada sincronización de los relojes. De esta manera se tendría la certeza de que el guardagujas estará realizando su trabajo a la hora prevista.

Ya sabemos cómo se deben sincronizar los relojes en este siglo para evitar accidentes catastróficos por no tener la misma hora en el reloj.

Ahora, el zancudo está dentro de la oficina, en Berna, en Europa, en la Tierra, en el espacio y aún vivo, pero ¿qué es el espacio?

De nuevo la sencillez de sus razonamientos y la poca pericia del cazador frustrado se hacen latentes, pues el zancudo acaba de escapar, pero Einstein considera que no todo está perdido, ya que el espacio es la relación de los cuerpos con los elementos utilizados para medir. Si quiero matar el zancudo, debo medir la distancia a la que se encuentra y calcular que la velocidad de escape no supere la velocidad de mi diestra poco entrenada - piensa Einstein-. Y, ¿cómo mido el espacio? Con una regla o una cinta métrica, simple. De nuevo suena el tren y nuestro científico imagina un escenario diferente: si el zancudo va en el tren y necesito saber la distancia a la que se encuentra para poder matarlo, ¿cómo la averiguo?

Imaginemos una barra rígida (la distancia a la que se encuentra el zancudo) moviéndose en el eje x con una velocidad constante (la velocidad del tren) y al estar en movimiento la barra ¿cuál será su longitud? Solo hay dos posibles soluciones.
a) El observador se mueve junto con la vara de medida con la barra que se trata de medir, y mide directamente la longitud de ésta superponiendo la vara de medida, igual que si los tres se hallaran en reposo. (Einstein e Infeld, 1939, p. 41).

En esta opción, estoy viajando dentro del vagón del tren e intentando matar al zancudo, pero si estoy en la estación y quiero averiguar la distancia a la que se encuentra al zancudo, puedo realizar la medición si al pasar cada uno de los extremos se envía un pulso al sistema estacionario. 
b) Por medio de relojes estacionarios colocados en el sistema estacionario y sincronizados, el observador determina en qué puntos del sistema estacionario están localizados los dos extremos de la barra en un momento dado. (Einstein e Infeld, 1939, p. 42).

Con la primera opción nos vemos obligados a hacer parte del sistema en movimiento, es decir, estar en el tren para matar el zancudo. La segunda es más interesante, nos plantea medir desde la estación la distancia a la que se encuentra el zancudo que va en el tren, en otras palabras, desde un sistema estacionario medir una barra que se está moviendo.

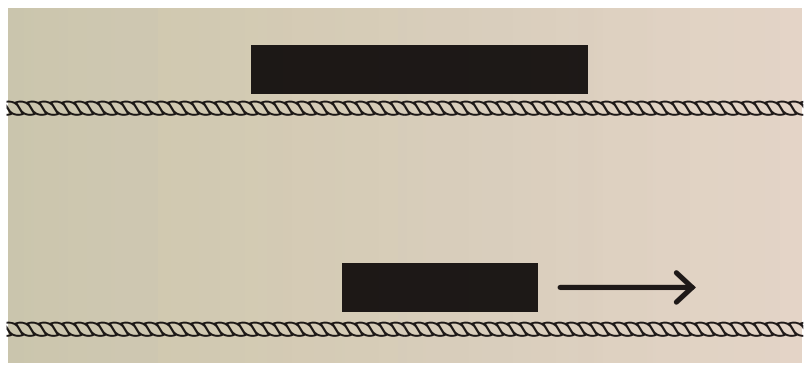

Ilustración 5. Barra fija (superior) y contracción de la barra fija en el sistema móvil (inferior). Fuente: Einstein e Infield (1939).

En la ilustración del libro de Einstein, se observa la barra superior estática y la inferior con una velocidad cercana a la de la luz, la medición de la persona en el sistema fijo de coordenadas tendrá una diferencia que corresponderá al tiempo que la luz tarda en viajar de la señal inicial a la señal final, observándose así una contracción y para su maquiavélico objetivo nuestro científico notará que la distancia es diferente a la que mediría estando en el vagón.

\section{Relativamente séptimo}

Imaginemos el siguiente escenario: somos chicos de 12 o 13 años; es un sábado en la tarde; estamos en nuestra casa llena de computadores, televisores, radios, celulares, internet, láseres, relojes, balones, ropa y cintas métricas, y todos estos aparatos están disponibles para nuestro uso. El fin de semana se pasa en un santiamén y llega el momento de ir a la aburrida escuela, donde siempre dan materias raras, supuestamente son muy importantes, en las que se habla de gente muy inteligente, pero extraña, de la cual solo quedan sus descubrimientos. De nuestro fin de semana lleno de juegos en línea, de chat con errores ortográficos y lenguaje abreviado, no queda nada.

¿Es culpa de la escuela ser aburrida?, ¿son los profesores tan viejos como para no notar las diferencias entre nuestros intereses y lo que nos enseñan? En la escuela hay que seguir ciertas reglas, se debe ingresar a las 6:10 a. m., si a lo largo de la semana llegas tarde más de tres veces, envían un reporte a tus padres. Entras y hay una aburrida formación, escuchas a los profesores quejarse de que no llevamos uniforme, repetir una y otra vez que debemos estudiar más y que la disciplina siempre nos llevará lejos; sientes que el tiempo no pasa y quieres volver a tu cama, a jugar Minecraft en tu tableta. Luego del sermón, pasamos a los salones y llega el profesor a contarnos sobre algún extraño pensador, a quien definitivamente se le ocurrieron cosas que a mí no. Hoy nos hablaron del tiempo, como algo rarísimo, algo que transcurre y es constante y nos mide a todos por igual, pero si esto es cierto, ¿por qué siento que en la formación y en la misa los segundos no pasan y el reloj se detiene? ¿Estoy alejado de lo que el profesor me enseña, o acaso, lo que el profe nos dice solo vale para su clase?

Luego de más de siete horas de estudio, termina la jornada escolar. Hoy el reloj tardó más tiempo en clase de matemáticas que en la de educación física; pero, ¿cómo es posible, si el reloj marca igual en todo momento? El caso es que ahora la prioridad es ir a ver el partido de la Champions, y que la Juve le gane al Real; los minutos del partido sí pasarán al mismo ritmo, pues los puedo ver en la pantalla del televisor, son solo 90 minutos, más adición. Cuando finaliza el partido y gana el Real, siento que el tiempo fue perdido, le hice fuerza a un equipo que jugó bien solo una parte del partido, pero no todo el tiempo; adicionalmente, perdí una 
apuesta con un profesor y ahora debo medir con mis zapatos el perímetro del colegio.

Después del partido, el sueño de ser el mejor de la cancha del barrio es más placentero, profundo y sagrado, menos para mi mamá que, aunque no va a clases de física sabe que a menos tiempo e igual distancia de la casa al colegio, hay que correr más o si no, nos coge la tarde, como si fuese Pac-Man comiendo a los fantasmas del juego. Esta vez, el reloj me jugó una mala pasada y llegué tarde, tendré que esperar un buen rato hasta que la fila se acabe y me anoten en la lista de retardos. El profesor, con quien perdí la apuesta, empieza a jactarse de su victoria y hoy en su clase deberé cumplir con lo pactado, medir con mis zapatos el perímetro del colegio, afortunadamente es pequeño como una caja de fósforos.

Hoy, como lo esperaba, él hizo que su clase fuese eterna y que el reloj marcara el tiempo a paso de tortuga, mientras nos comentaba los placeres de haber ganado más de una apuesta sin siquiera mover un dedo, solo por confiar en el mejor equipo. A la velocidad de la luz recordó nuestra apuesta y me puso a medir todo el perímetro del colegio, mi cálculo falló, ese día llevé unas zapatillas más grandes y mi medida varió, fue de 893 zapatos, con un metro hubiese sido más rápido, aun así, entendí la diferencia que hace el instrumento en la medición, pues si quiero medir el grosor de una hoja no voy a utilizar un metro, pero si quiero saber la distancia de aquí a Medellín, no debo utilizar una regla, pero esas son solo bobadas que se me ocurren cuando me distraigo. Cuando finalizó la medición también terminó la clase; espero que mañana el profe nos sorprenda con alguna actividad interesante.

Luego de volver a casa, no quería más que dormir, pero mis 13 horas de sueño pasaron en cuestión de un parpadeo y debo correr, porque, como cosa rara, voy sobre el tiempo, y como mi mamá me dijo: "Sí la distancia es igual y el tiempo es poco, ¡corre hijo!". La formación fue más aburrida esta vez, a algunos chistosos de grado once se les dio por hacer trampa en un examen de matemáticas y como el profe era el asesor de once cree que todos somos iguales, y sí, pero que aburrido escucharlo quejarse de algo que los profes también hicieron en su momento.

Aunque furibundo, el profe llegó con unas hojitas de papel que tenían dos preguntas, fue raro, porque él no pierde tiempo de clase, y aún más raro era la simplicidad de las preguntas: ¿qué es el tiempo?, ¿qué es el espacio? La primera fue un poco más sencilla, recordé mis carreras y dije: "El tiempo es una manera de saber cuánto me demoro en llegar a un lugar o hacer algo que me gusta o no". Para el dibujo pensé en mi peor enemigo, el reloj de la sala de mi casa, por el cual he ganado más de un regaño de mi mamá.

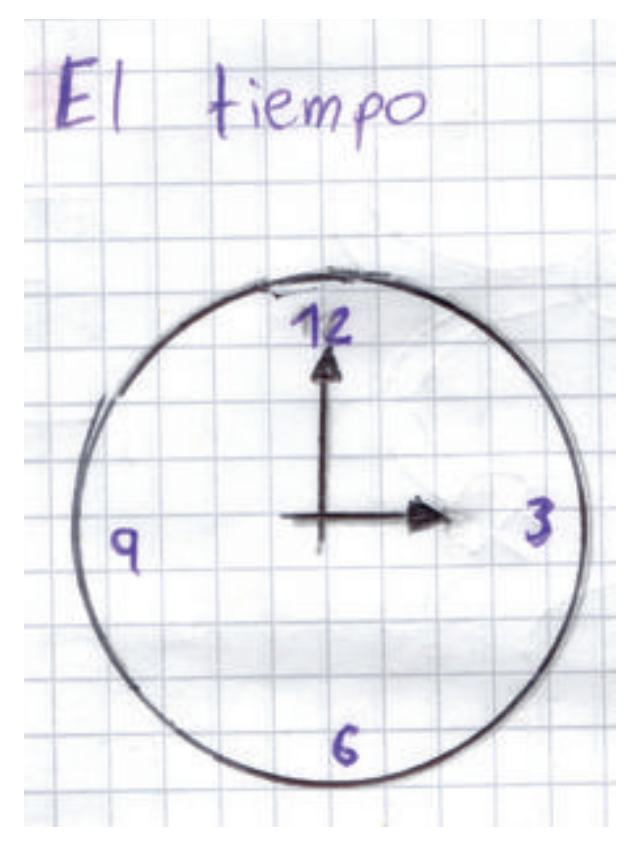

\section{Ilustración 6. Representación del tiempo} por un estudiante

Con la pregunta del espacio me demoré más, no entiendo muy bien qué es eso que llamamos espacio, aun así, respondí: "El espacio puede ser todo: los planetas las estrellas, el lugar que ocupa cada cosa", y en la tierra pensé en el espacio vacío. El profe nos sorprendió a todos, esa fue su clase, dos preguntas y ¿quién sabe para qué?, tal vez le dio pereza hacer clase normal. 


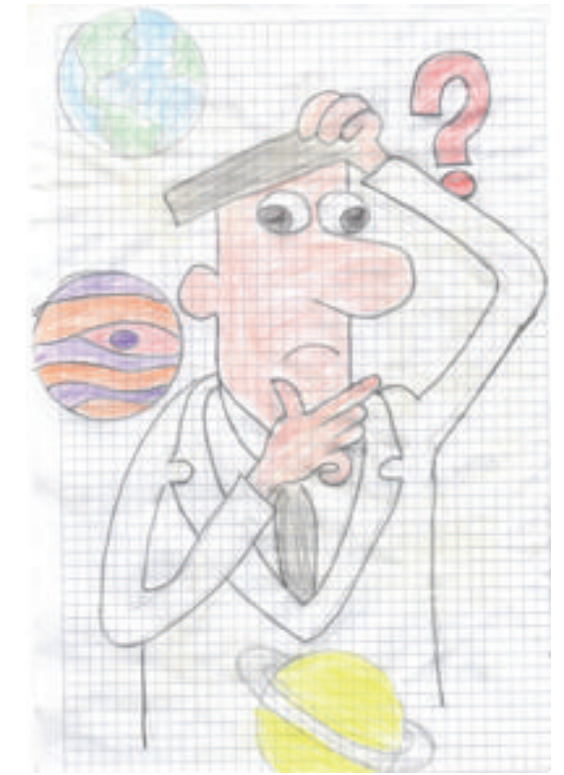

Ilustración 7. Representación del espacio por un estudiante

La siguiente clase, superando un poco lo de la copia y los regaños habituales, vimos la película Alicia a través del espejo, en la que el tiempo es un reloj. Hubo algo que entendí solo al darme cuenta de que me pasaba a diario, aunque usualmente ni lo notara, cuando el gato, sonriente, dice:"Estoy sobre el tiempo", me imaginé corriendo como loco para llegar a tiempo; pero, ¿qué es el tiempo? Eso se me ocurrió, pero me dio pena preguntar, porque no quiero que el profe piense que soy un burro, espero que se le ocurra contarnos. Así es, resulta que el tiempo y las distancias no son tan distintas, dependen del instrumento con el que se mide y resulta que hay más que segundos, minutos y horas para medir tiempo, también existen milenios $y$, medidas muy pequeñas, los microsegundos que son 1/100000 parte de segundo, eso es muy poquito, ni siquiera alcanzaría a pestañar.

Otra cosa que me interesó es la manera en que Alicia cambia de tamaño al atravesar el espejo, pero acaso ¿ella se hizo más pequeña?, o ¿todos los objetos en ese mundo de maravillas eran muy grandes?, no aguanté la curiosidad y pregunté, contrario a lo que había supuesto, el profe me felicitó y hasta me subió unas décimas, porque fue una pregunta interesante, pero me dijo que aún no la respondería. Con todas las preguntas que teníamos, la clase se extendió y tomó parte del descanso, aun así, no importó, nuestro interés estaba vivo, el profe nos dijo que las preguntas las debíamos responder nosotros, pero aún no entiendo cómo, la siguiente clase promete ser interesante. Luego de las carreras matutinas, llegamos a la siguiente clase, el profe tenía unas hojas con una cuadrícula de ocho cajones, en los impares (uno, tres, cinco y siete), debíamos dibujar la historia real de la película, y en los pares (dos, cuatro, seis y ocho) debíamos imaginar cuál es la escena que añadiríamos para que la película tenga mayor sentido para nosotros. Es divertido porque me siento como un director de cine, imaginando cuál será el paso a seguir, yo cambiaría parte del final, si se rompe la armonía del tiempo cuando la reina se encuentra con su versión del pasado, haría que no se congelara todo inmediatamente, porque si pudiese verme en el pasado, no dejaría que me cayera de la bicicleta, como me sucedió un montón de veces, o podría saber las respuestas del examen y mi mamá no me castigaría, aunque sería a su vez algo un tanto vacío, porque si puedo saltar en el tiempo, podría prever cosas, pero si todo es como en la película, igual las cosas sucederán, lo cual es frustrante. La posibilidad de que algo así pueda ocurrir, aunque sea solo en mi mente y parezca imposible, me llena de emoción. El profe terminó la clase con algo que no pude olvidar, nos dijo: "Puedes empezar a hacer lo imposible, si crees que es posible", en ese momento pensé que tal vez fuera posible viajar al futuro, aunque mi mamá ya no me prepararía comida rica, así que no sé si irme o quedarme, pero imaginarlo resulta sumamente interesante. 


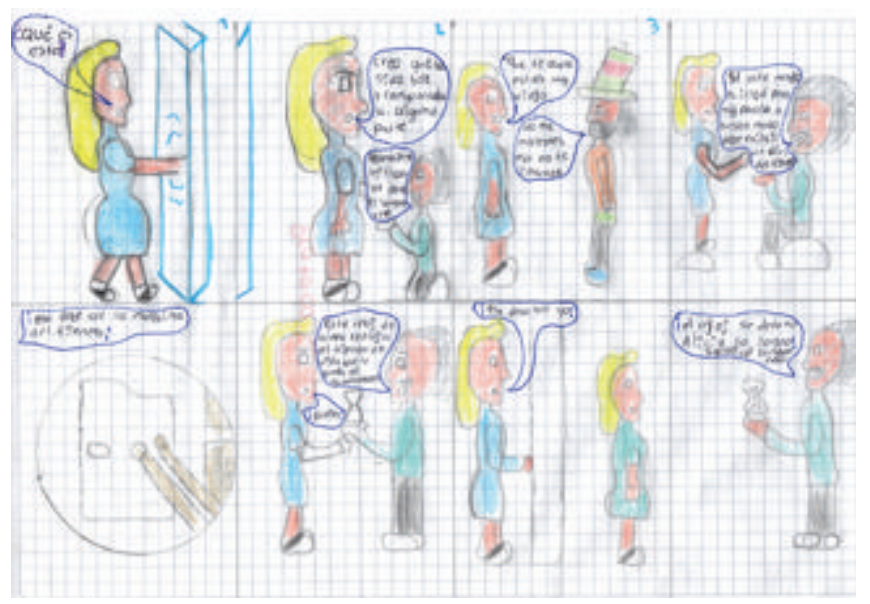

Ilustración 8. Historieta por un estudiante

Luego de clase, salimos a jugar, pero había algo en la cara de todos, teníamos mucha curiosidad, así que empezamos a hablar de lo fascinante que sería encontrarnos en unos años y saber si fuimos astronautas o vendedores, si tendríamos plata o si podré llegar a jugar en el Barcelona. Recordé uno de mis capítulos preferidos de Phineas y Ferb, "el viaje cuántico" y mientras lo pensaba, me preguntaba ¿qué pasaría si el presente ya hubiera sido alterado por alguien del pasado o del futuro? ¿Cómo podríamos saberlo?, con este tema me surgen muchas preguntas.

En esta clase, el profe, aparte de seguir celebrando la victoria de su equipo, nos puso a medir el salón en grupos, la cancha, el arco y hasta el tablero, con diferentes instrumentos, cada grupo elegía dos estudiantes y realizaba la medición. No entendimos para qué hizo esta actividad, pero mis compañeros notaron que las cosas se miden con referencia a otras cosas, tal como lo había pensado mientras pagaba mi apuesta.

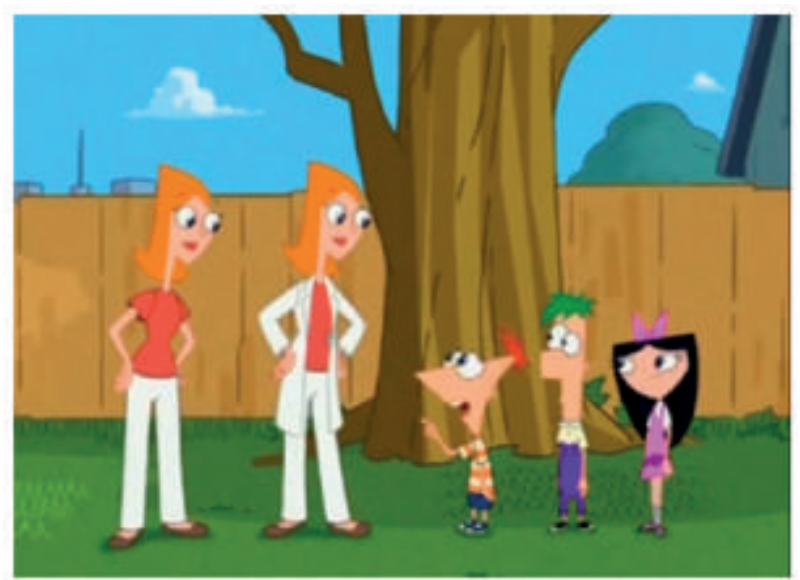

Ilustración 9. Viaje cuántico de Phineas y Ferb Fuente: Phineas y Ferb Wiki (2010).

Luego, el profe sacó tres bandas elásticas y nos pidió que "midiéramos" los mismos objetos, aunque nos pareció broma, lo intentamos, pero si las estirábamos, el tablero mediría una banda muy estirada a lo largo y una no tan estirada a lo ancho, los otros grupos también lo hicieron aunque nos parecía una tontería, pues no podríamos determinar algo que sirviera de patrón para medir los objetos, a menos que no estiráramos las bandas, con lo cual podríamos llegar a un cierto acuerdo, pero aun así era difícil de medir.

De nuevo, el profe planteó una pregunta que nos hizo pensar: si eso que nos rodea es el espacio y solo podemos dar cuenta de él porque lo medimos con objetos sólidos, ipero con bandas de caucho o un espacio no rígido sería diferente? Además, nos mostró una imagen de un cuadro de un pintor llamado Salvador Dalí, titulado La persistencia de la memoria. En él se ven unos relojes que parecen derretidos, pero si el espacio fuese diferente, todo esto que hemos percibido, ¿no es real? El profe culminó con otra frase de la película, ¿quién define qué es real y qué no lo es? Ahora estamos un poco más confundidos, también más interesados, pero el profe nos comenta que no podemos dedicar muchas más clases a estos temas, pues debemos continuar con los temas que nos faltan, antes de que acabe el año escolar. Nos esperan asuntos como la regla de tres y el álgebra, aunque, personalmente, este tema me interesa más. 


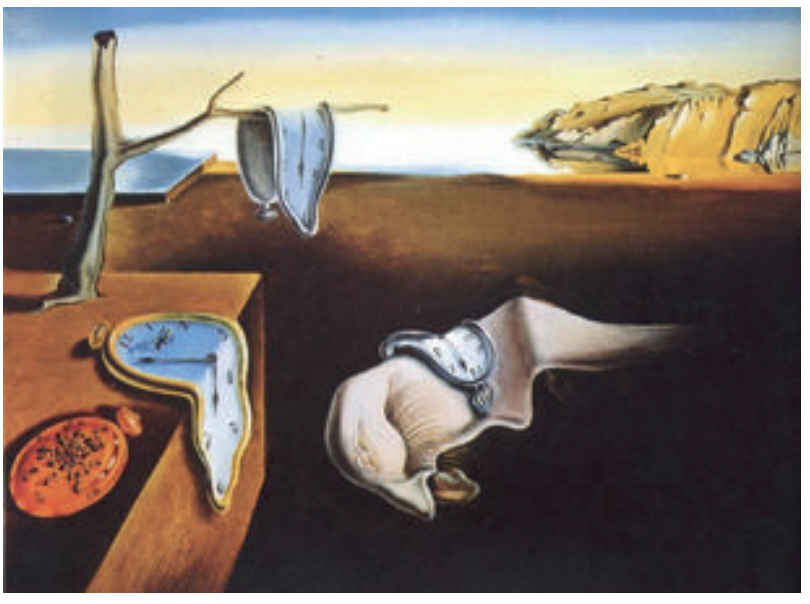

Ilustración 10. La persistencia de la memoria Salvador Dalí.

Fuente: WikiArt.org. (2015)

Mis juegos de fútbol y de Minecraft siguen siendo iguales, me agrada jugarlos, son algo muy diferente a mi escuela, me divierten. A veces me pregunto si los profes se divierten enseñando, de no ser así, la escuela debe parecerles aún más aburrida que a mí, y eso ya es mucho decir. Contrario, a lo que pensábamos, el profe nos dice que todas esas clases fuera de lo común en las que nos planteó un montón de preguntas sobre el tiempo, el espacio y viajes al pasado estaban planeadas.

En la clase del jueves vimos una película que llamó mi atención, se llama Interestelar, es muy buena, pero con demasiados asuntos raros sobre los viajes en el tiempo, es algo así como envejecer más lento si estás cerca de un planeta, pero si estás en la tierra envejeces al mismo ritmo que los demás; pero, ¿exactamente a qué se refiere?

En la última película se hablaba del trabajo de un grupo de científicos encabezados por Einstein que empezaron a creer en lo imposible, pues antes de que plantearan la posibilidad de los viajes en el tiempo, ni siquiera se pensaba en ello. Este grupo inclusive fue más allá y, hace más de cien años, demostraron matemáticamente que se podían lograr hazañas como las vistas en la película, que el tiempo es relativo y que el espacio se puede deformar, ideas nada habituales entre el común de la gente. Para nosotros esto dejó de ser tan solo el tema de algunos capítulos de series y novelas cuando lo debatimos en la clase de física y se convirtió en el tema más apasionante.

Además, descubrimos que el espacio y el tiempo no son cosas tan lejanas: quién puede definir el tiempo si no es con un reloj, quién define el espacio si no es con una barra para medir. Según la teoría, el espacio y el tiempo terminan siendo algo inseparable, una sola cosa que constituye la cuarta dimensión. Aunque ahora tiene sentido, antes ni se me pasaba por la mente, pero qué es un partido de fútbol si no hay tiempo y un lugar como el Camp Nou para saber que no durará eternamente, sino hasta que el árbitro indique el final. Conocer solo uno de los datos no nos permitirá saber cuándo será el partido; desde luego hay muchos partidos en ese estadio, pero, ¿a cuál ir? Además, todos duran en promedio 90 minutos, pero, ¿qué día de la semana se jugará?, o ¿si esta fecha es en otro estadio?, es obvio que debo saber el día, la hora y el lugar para poder asistir.

Einstein dedujo todo esto, no sé si es un genio o solo un observador cuidadoso, pero ahora lo entiendo, quizá podría enseñarlo a mis compañeros con facilidad, pues no es tan complejo como pensaba, al final la genialidad consiste en hacer que las cosas sean más sencillas.

\section{Reflexiones}

Todo el trabajo que se mostró anteriormente solo tiene sentido cuando se ve desde la perspectiva de un docente que desempeña un papel activo no solo como investigador, sino también como generador de conocimiento.

Estar en un ambiente escolar requiere pericia al momento de enseñar y también una gran destreza para trabajar bajo presión, es una de las consecuencias de trabajar con seres pensantes - aunque a veces nos quejamos de lo último-. Hay que saber manejar la clase, el informe, la nota, la disciplina y, por si no fuera suficiente, la atención a padres, la respuesta a las preguntas 
por la plataforma y hasta los roces entre compañeros de clase, todo en un santiamén. Suena estresante y lo es, pero posiblemente si has tenido una clase como titular, entenderás de qué hablo, si no, imagina el escenario. Estamos hablando solo de la dimensión profesional de tu vida, no hemos hablado de la personal y académica, transversales a nuestro diario vivir. Tal vez suena dramático, sin embargo, el estrés no es el problema, lo es la monotonía.

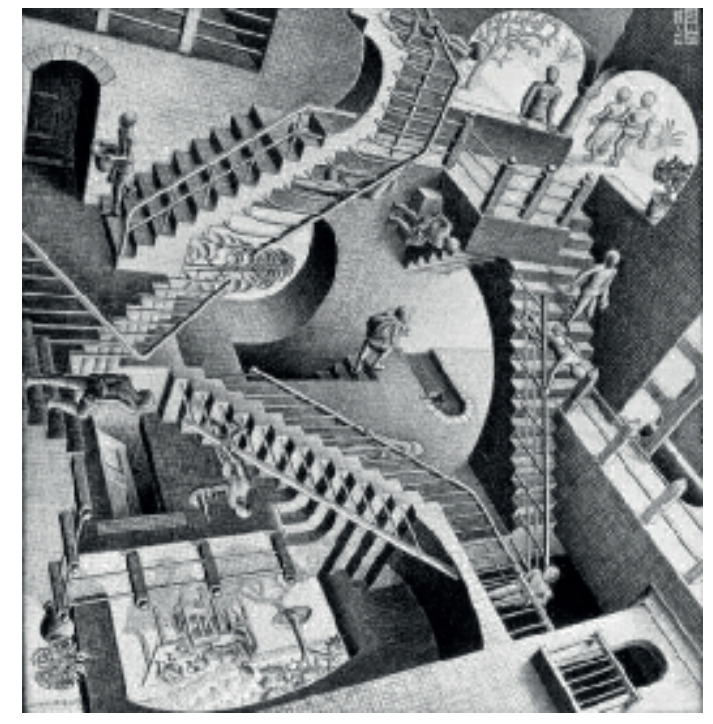

Ilustración 11. Relatividad de Escher Fuente: Cultura Colectiva (2013).

Enseñar durante cinco años las mismas materias, de la misma forma, se hace reiterativo y poco apasionante, por eso, la alternativa es hacer de nuestra labor algo interesante, innovar en el día a día de nuestro quehacer pedagógico. Al iniciar una clase o un tema, a mi juicio, deberíamos empezar a conocer lo que los estudiantes piensan, pero también contextualizar nuestros temas en la cotidianidad de los chicos.

Hablar de los dibujos animados que les gustan, de arte - la imagen de Escher denominada Relatividad les encantó a los chicos-y de cine son buenas estrategias para introducir temas de física. Yo lo hice de la siguiente manera:

“Chicos, ¿han pensado en la posibilidad de viajar en el tiempo?, ¿creen ustedes que hay vida en otros lugares del universo?, ¿quién ha visto el capítulo de Phineas y Ferb en el que construyen la máquina del tiempo y viajan al pasado?, ¿han visto películas en las cuales se viaje al pasado?, ¿han tenido alguna vez los llamados déjà vu?, ¿existe la posibilidad de predecir el futuro?". Luego de unas intervenciones ya tenía su atención, ahora es el momento de cuestionarlos acerca de mis intereses: "Para ti, ¿qué es el espacio?, ¿qué es el tiempo? Por favor, escriban sus respuestas para compararlas, ¿te atreverías a dibujar los conceptos?".

A la pregunta ¿qué es el tiempo?, algunos de los chicos contestaron de la siguiente forma:

Samy: Es algo que se utiliza para medir lo que ha pasado. Es infinito, no se puede devolver y se puede medir de diferentes formas.

J. J.: Es lo que se gasta a diario ya sea en algo productivo o en algo no tan productivo. Es algo que transcurre.

Sofi: Es una manera de saber cuánto me demoro en llegar a un lugar o hacer algo que me gusta o no.

La imagen indiscutible del tiempo fueron los relojes, bien sea de arena, digitales o análogos.

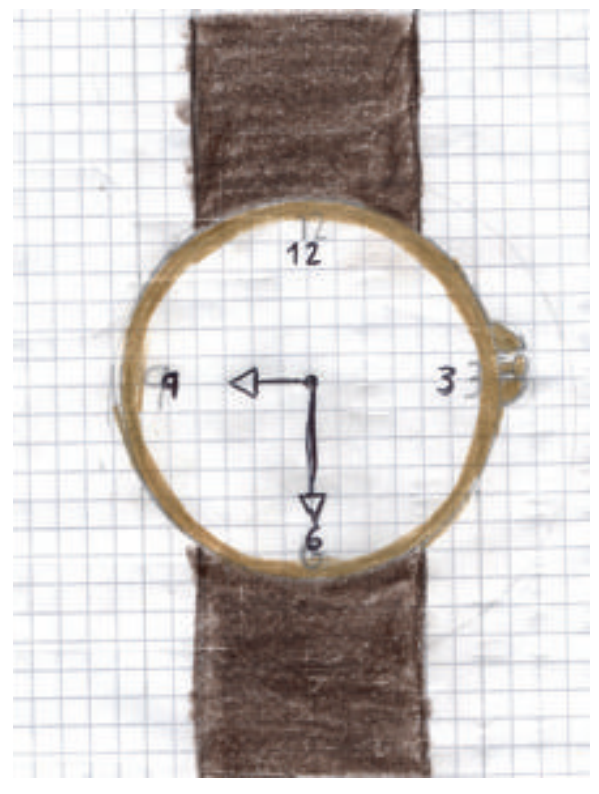

Ilustración 12. Representación del tiempo para un estudiante 
A la pregunta ¿qué es el espacio?, los chicos respondieron:

Samy: Es un medio físico que ocupa un lugar y si no hay objeto de todas maneras el espacio sigue estando ahí.

J. J.: Algo que la mayoría no conoce, otros planetas, galaxias, etc.

Sofi: El espacio puede ser todo, los planetas las estrellas, el lugar que ocupa cada cosa.

La mayoría de los estudiantes asociaron el espacio al sistema solar y a las galaxias, otros estudiantes lo relacionaron con un parque, con un lugar amplio.

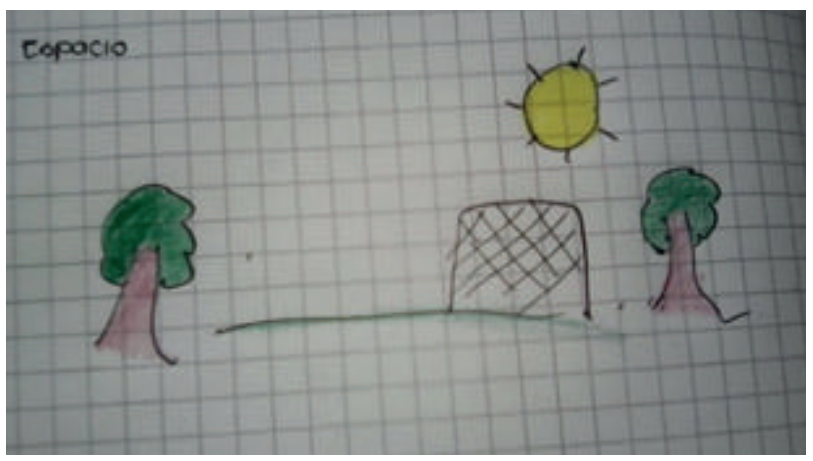

Ilustración 13. Representación del espacio para un estudiante

Lo anterior fue el resultado de nuestra primera clase. Ya tenía una evidencia y un dibujo de conceptos aparentemente muy sencillos.

Para la siguiente clase, con los chicos se planeó ver una película muy cercana a su contexto y que permitiese relacionar las preguntas de la primera sesión. La elección fue proyectar Alicia a través del espejo, debido a su contenido crítico frente a los conceptos de espacio y tiempo reinantes en la Europa del siglo XVII. Lewis Carroll (Carroll, 1994), a través de una historia infantil, hizo que estos conceptos de base de la física fuesen pensados de nuevo y revisados posteriormente por la comunidad científica, lo que culminó con los trabajos de Einstein. En la película, dirigida por Bobin y Woolverton (2016), se desarrolla un concepto espacio-temporal relativista tomado del libro de Carroll, y lo muestran de una manera didáctica que posibilita aproximar a los estudiantes al concepto que se quiere trabajar. De esta actividad, lo más fructífero fueron las preguntas, para los chicos fue muy interesante el cambio de tamaño de Alicia al atravesar el espejo, la pregunta que les hice fue: " ¿Se hizo más pequeña o en ese mundo las cosas eran más grandes?". También observaron que el tiempo es un reloj, lo cual no les sorprendió, pues como vimos en los dibujos era algo que ellos ya pensaban.

Quedaron encantados con la idea de los viajes en el tiempo y un poco inconformes por el final de la película, por ello, se decidió realizar la actividad cuatro, que se describirá más adelante.

En la tercera clase, se sentía en los chicos una actitud un tanto más relajada en comparación con el ambiente habitual de la clase de matemáticas (en el colegio ven física en décimo grado y tomamos horas de la clase de matemáticas para la implementación de la estrategia de aula que se está socializando). Les solicité que conformaran tres grupos de tres estudiantes y un grupo de cuatro, de modo que nadie quedara solo, para realizar la actividad, la idea es hacer la medición con diferentes instrumentos de algunos objetos del salón y del colegio. Les pedí a los chicos que midieran diferentes objetos con cualquier instrumento, ellos eligieron zapatos, corbatas y reglas: hicimos la medición del salón y de la cancha, con zapatos, con reglas y con corbatas. Lo cual fue sencillo y se realizó tres veces en cada objeto para rectificar la medida.

Tabla 1. Datos tomados en clase de objetos

\begin{tabular}{|l|l|}
\hline Objetos & Medida \\
\hline Pupitre (lado) & $37 \mathrm{~cm}$ \\
\hline Arco de la cancha & 12 zapatos \\
\hline Tablero del salón & 5.5 corbatas \\
\hline $\begin{array}{l}\text { Largo cancha de } \\
\text { microfútbol }\end{array}$ & 43 zapatos \\
\hline
\end{tabular}


Posteriormente, realizamos un ejercicio mental, la situación hipotética fue la siguiente: "Se debe realizar la misma medición hecha anteriormente, pero ahora se deben cambiar los objetos utilizados para medir por una banda elástica, entonces, ¿qué sucedería?"

Los estudiantes Ilegaron a la siguiente conclusión:

Si lo hubiéramos hecho con una banda elástica sería mucho más difícil realizar las mediciones, porque esta no tiene figura establecida. Entonces la medida es mucho más difícil [de] hacer porque la banda se puede estirar y la medición se alteraría. Se podría hacer si se deja la banda en su forma neutral o sin estirar.

Al observar el interés e inconformismo de los estudiantes con el final de la película Alicia a través del espejo, les propuse que plantearan su propio final en una historieta de la película que tuviese ocho espacios, los impares eran eventos de la película y los pares eran el paso que ellos agregarían si fueran los directores de la película. Algunos estudiantes incluyeron muertes en sus finales, otros la detención definitiva del tiempo y otros prefirieron dejar a Alicia con la familia del sombrerero.

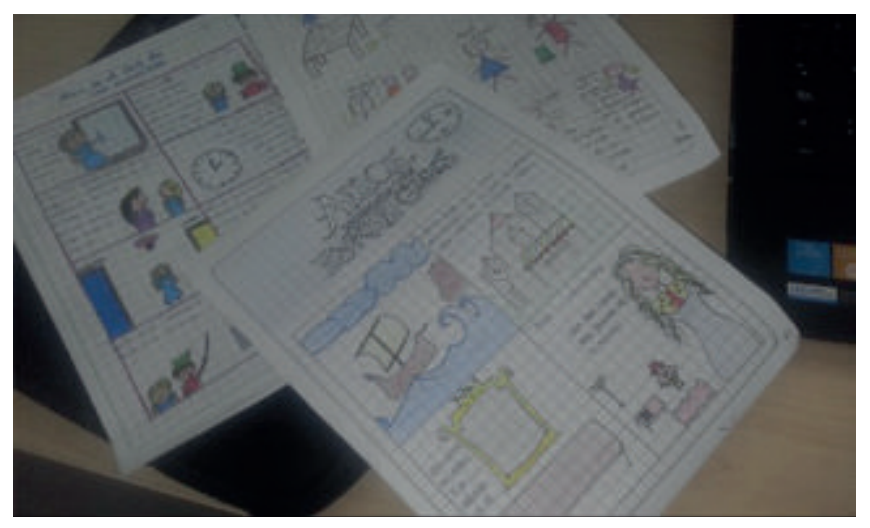

Ilustración 14. Collage de historietas

Las actividades previstas eran cinco, pero se tomó la decisión de mostrar una última película. Interestellar (Nolan, 2014) fue la cereza del postre, los jóvenes quedaron fascinados con la idea del tiempo relativo, algunos pudieron comprender por qué llegaban tarde a todo lado, otros hasta lloraron al ver que al final la hija muere de vieja y el padre apenas tiene unos años más que cuando partió, la película les causó gran emoción y terminada la ronda de preguntas sobre agujeros negros, agujeros de gusano, se planteó la pregunta que a mi juicio validó este trabajo:" ¿Acaso no podríamos pensar que el padre simplemente viajó en el tiempo para ver morir a su hija?". Situación ideal, pues privilegia la diferencia del tiempo para los observadores.

Ya estábamos preparados para culminar este ciclo de implementación que finaliza como lo empezamos, con dos preguntas sencillas.

Para ti, ¿qué es el tiempo?

Samy: Es algo que va hacia adelante como la marcha del reloj que nunca se devuelve.

\begin{abstract}
J. J.: Es lo que ayuda a estar conscientes de sucesos que pasen alrededor de la vida. El tiempo está en distintas cosas y objetos.
\end{abstract}

Sofi: Para mí, el tiempo es una percepción diferente según la actividad desarrollada, el tiempo es un reloj como en la película que muestra que se agota la vida con cada minuto vivido

Para ti, ¿qué es el espacio?

Samy: Es todo lo que nos rodea, pues hay diferentes clases de espacios, espacio vacío, espacio público o espacio privado.

J. J.: El espacio son todos los cuerpos que llenan lo que conocemos como galaxias.

Sofi: Es una forma diferente de vivir dependiendo del lugar en el que se encuentre, es la relación con los demás y con el mundo.

La imagen a continuación representa el espacio y el tiempo como un todo y no como dos conceptos separados, por ello es tan interesante. 


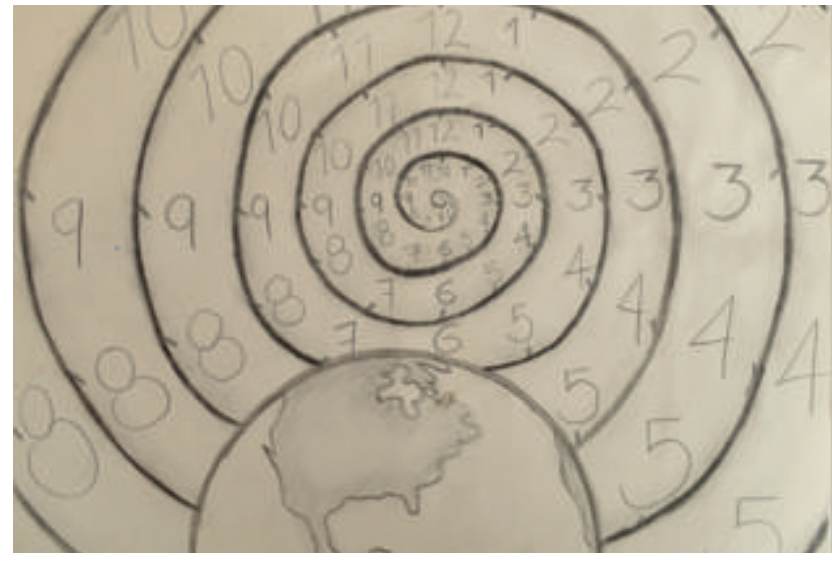

Ilustración 15. Dibujo de Ceci sobre el espacio-tiempo
Observé un mayor interés por parte de los estudiantes, con preguntas y situaciones que no eran fáciles de explicar para ellos como ise puede viajar en el tiempo?, ¿es posible la teletransportación?, entre otras. Esto permitió que la clase avanzara y que los estudiantes percibieran la física como un campo interesante y novedoso, en palabras de Bachelard (1975), descubrieron la ciencia actual y no la de sus abuelos que les aburriría y les parecería tediosa.

El trabajo con los chicos puso de presente la posibilidad de llevar estos contenidos a la educación básica, en contraste con la idea más generalizada de las dificultades que representan la asumida complejidad de estos temas y la edad de los estudiantes.

Tabla 2. Paralelo entre las concepciones sobre el espacio-tiempo de Einstein y de los estudiantes de séptimo grado

\begin{tabular}{|c|c|c|}
\hline & ¿Qué es el espacio? & ¿Qué es el tiempo? \\
\hline Einstein & $\begin{array}{l}\text { El espacio no es definido explícitamente } \\
\text { en el artículo de 1905, sin embargo, al } \\
\text { hablar de interacción de cuerpos dice: } \\
\text { "El observador se mueve junto con la } \\
\text { vara de medida con la barra que se trata } \\
\text { de medir, y mide directamente la lon- } \\
\text { gitud de ésta superponiendo la vara de } \\
\text { medida, igual que si los tres se hallaran } \\
\text { en reposo" (Einstein et al., 1993, p. 38). } \\
\text { El espacio es la relación de cuerpos que } \\
\text { miden y son medidos. }\end{array}$ & $\begin{array}{l}\text { Para la "definición de 'tiempo' bastaría con } \\
\text { sustituir 'la posición de la manecilla peque- } \\
\text { ña de mi reloj' por 'tiempo"' (Einstein et al., } \\
\text { 1993, p. 37). }\end{array}$ \\
\hline $\begin{array}{l}\text { Consenso de la } \\
\text { última clase }\end{array}$ & $\begin{array}{l}\text { El espacio es lo que medimos con otros } \\
\text { cuerpos, aunque se encuentre lejos } \\
\text { como las galaxias. }\end{array}$ & $\begin{array}{l}\text { El tiempo es la forma en la que notamos el } \\
\text { cambio de los eventos. }\end{array}$ \\
\hline
\end{tabular}




\section{Referencias}

Albert Einstein. (Octubre 1, 2017). Wikipedia. Recuperado de: https://es.wikipedia.org/wiki/ Albert_Einstein

Bachelard, G. (1975). La actividad racionalista de la física contemporánea. Buenos aires: Siglo XX.

Bobin, J. (Director), y Woolverton, L. (Guionista) (2016). Alicia a través del espejo [Película]. Estados Unidos: Walt Disney Pictures.

Carroll, L. (1994). A través del espejo y lo que Alicia encontró al otro lado. Madrid: Alianza editorial.

Cultura Colectiva. (Noviembre 8 de 2013). Las obras imposibles de M.C. Escher. Recuperado de: https://culturacolectiva.com/arte/lasobras-imposibles-de-m-c-escher/

Einstein, A., y otros. (1993). Grandes obras del pensamiento. En M. Paredes, La teoría de la relatividad: Sus orígenes e impacto sobre el pensamiento moderno (pp. 61-67). Barcelona: Atalaya S. A.

Einstein, A., e Infeld, L. (1939). La física aventura del pensamiento. Buenos Aires: Losada S. A.

Guayara, S. (2017). La teoría especial de la relatividad: reglas fijas y relojes con estudiantes de grado séptimo. Bogotá: Universidad Pedagógica Nacional.
La Bioguia. (Agosto 1, 2017). La paradoja del gemelo de Einstein que solo alguien inteligente como él puede resolver. Recuperado de: http://www.labioguia.com/ notas/la-paradoja-del-gemelo-de-einsteinque-solo-alguien-inteligente-como-el-puederesolver

La Red. (Julio 17, 2017). Científicos hacen realidad la teletransportación hacia el espacio. Recuperado de: http://lared.cl/2017/lared-social/cientificos-hacen-realidad-lateletransportacion-hacia-el-espacio

Ministerio de Educación Nacional (MEN) (2006). Bogotá: Ministerio de Educación Nacional.

Nolan, C. (Director) (2014). Interstellar [Película]. Estados Unidos: Paramount Pictures y Warner Bros. Pictures.

Phineas y Ferb Wiki. (Junio 10, 2010). El viaje cuántico de Phineas y Ferb. Recuperado de: http://es.phineasyferb.wikia.com/wiki/El_ Viaje_Cu\%C3\%A1ntico_de_Phineas_y_Ferb

WikiArt.org. (Junio 4, 2015). La persistencia de la memoria. Recuperado de: https://www. wikiart.org/es/salvador-dali/la-persistenciade-la-memoria-1931

Youtube. (Junio 22, 2015). Final de Interestellar [video]. Recuperado de: https://www. youtube.com/watch?v=Xyh4uRzFQ1Q 


\section{Anexos}

La problemática vivida en la física a inicios del siglo XX se debió a la no correspondencia entre los experimentos y la teoría, pues las experiencias llevadas a cabo en dicho siglo y las bases teóricas predecían un comportamiento en las experiencias y los resultados evidenciaban otros. Ese fue el caso del experimento de Trouton-Noble, citado por Einstein en el artículo de 1905, sobre la electrodinámica de los cuerpos en movimiento, para el cual fue necesario revisar los conceptos de espacio y de tiempo para que la no correspondencia se limara haciendo posible su explicación con las mismas leyes de la física.

Algunos de los teóricos dentro de la literatura consultada que apoyan la tesis en Michelson-Morley, como el bastión de la TER son, Gaston Bachelard, Sánchez Ron, Fabio Vélez y los textos de divulgación científica para los colegios. Incluso lan Stewart, aproxima el experimento de Michelson-Morley como una de las causas menores que ocasionaron la relatividad.

Por otra parte, los teóricos que se inclinan hacía el experimento de Trouton-Noble (1903), cabe recalcar que el texto de Galison hace referencia a los dos experimentos y no se inclina en mayor medida a alguno, y a nuestro juicio Einstein, al hablar de la situación del imán y el conductor. Es, por tanto, de suma importancia volver a las fuentes de los autores de las teorías, consultar sus inquietudes y los problemas que hicieron plantear como solución las teorías. (Guayara, 2017).

Con el estudio histórico-crítico se contrastó la posición de algunos teóricos que muestran que Einstein quería dar solución al problema planteado por Michelson-Morley y otros que plantean el interés de Einstein por dar explicación al experimento de Trouton-Noble. Al analizar el texto base de la teoría (artículo de 1905), no se evidencia que retome el experimento discrepante de Michelson-Morley, por el contrario, hace referencia textual al problema planteado por Trouton-Noble.

Los estudios histórico-críticos se plantean con base en la investigación como una opción para que los docentes desarrollen su labor como investigadores y contextualicen los conocimientos según los intereses y cuestionamientos de los estudiantes. 


\section{Eventos de la Facultad}

\section{Jornada del Educador Matemático}

La Jornada del Educador Matemático (JEM) es un evento académico, cultural y recreativo del Departamento de Matemáticas creado hace mas de 25 años, en el que, cada semestre, los miembros de la comunidad de educadores matemáticos de la Universidad Pedagógica Nacional y de otras instituciones educativas pueden compartir sus experiencias, descubrimientos, ideas e intereses con las nuevas generaciones de docentes de matemáticas.

En una charla sostenida con Pre-Impresos, el profesor William Jiménez, miembro del comité organizador de la cuadragésima primera versión de la JEM, nos cuenta algunos aspectos de la historia, trayectoria y perspectivas de este evento.

\section{Pre-Impresos: ¿Qué es la Jornada del Educador Matemático?}

William Jiménez (WJ): Es un espacio académico que nació hace varios años con el propósito de propiciar el intercambio académico, de manera que los estudiantes del Departamento de Matemáticas pudieran comunicar sus propuestas de trabajo de grado, de práctica y los trabajos que estaban desarrollando en sus clases, asimismo, el evento brinda la oportunidad para que los profesores le cuenten a sus estudiantes en qué están trabajando. Hoy, la JEM es un espacio más grande al que traemos profesores de otras universidades dedicados al estudio de las matemáticas a que nos cuenten qué están haciendo en su respectiva universidad y a que conozcan cuál es el trabajo que realizan nuestros estudiantes y profesores. También traemos algunos colegios, como el Instituto Pedagógico Nacional (IPN), que tiene un grupo de niños talento que vienen y nos cuentan casi todas las jornadas qué es lo que están haciendo. Es un evento académico en el que intercambiamos conocimiento, además de una ocasión para conocernos más como departamento y también con otras universidades, en la que también realizamos actividades culturales y recreativas.

Pre-Impresos: ¿Cuál es la finalidad de la JEM?

WJ: El evento tiene varios propósitos. La idea es que estudiantes y profesores sometan a un juicio social sus productos, de manera que los estudiantes conozcan lo que investigan sus profesores y qué se les propone, por ejemplo, como trabajo de grado. Asimismo, conocer el trabajo de colegas de otras instituciones - como es el caso de la Universidad Nacional, de la Universidad Militar Nueva Granada, de la Conrad Lorenz, de la Sergio Arboleda - que vienen a presentar lo que están haciendo. Este intercambio de ideas nos genera posibilidades para producir conocimiento ya sea en un trabajo de grado, en un trabajo de investigación o proyecto de Facultad y, a la vez, fortalecer vínculos con otras instituciones tanto académicas como culturales.

Pre-Impresos: A la fecha, ¿qué hechos se puedan resaltar de la Jornada del Educador Matemático?

WJ: Varios, por ejemplo, se ha asumido este espacio como una responsabilidad de los estudiantes del Departamento de Matemáticas. En este momento, hay un equipo consolidado de unos 12 estudiantes que, semestre a semestre, se encargan de la organización del evento, aunque no son los únicos que lo asumen como propio. Todos los estudiantes del Departamento de Matemáticas participan en la organización de este espacio, ya sea como jefes de salón o ponentes, y motivan la participación 
y asistencia a las presentaciones y conferencias programadas, pues este es un evento del que nos sentimos orgullosos. Además, los contactos con otras universidades nos posicionan en el ámbito académico y también nos permite retroalimentarnos mutuamente en el trabajo realizado. Asimismo, al inicio de todos los semestres, recibimos correos de estudiantes de otras universidades con preguntas como cuándo se va a realizar la siguiente jornada, cómo pueden enviar sus trabajos, lo que muestra que es un espacio reconocido y bien posicionado entre los pares académicos, esos son los hechos que se pueden resaltar, entre muchos otros.

\section{Pre-Impresos: ¿A quién va dirigida la JEM?}

WJ: Va dirigida fundamentalmente a la comunidad académica del Departamento de Matemáticas, pero esto no excluye la participación de estudiantes de otras universidades de carreras afines, de estudiantes de la Facultad de Ciencia y Tecnología y, en general, de cualquier persona o grupo que estén interesados en participar, pues simplemente deben inscribirse y venir a mostrar lo que están haciendo. Hemos tenido estudiantes de física, incluso han participado grupos de boy scouts con trabajos sobre aplicaciones de las matemáticas a su campo. En anteriores jornadas también se destaca la participación de las universidades Nacional y Distrital, asimismo, del IPN y el Manuela Beltrán como colegios de práctica que nos acompañan de manera frecuente en la jornada.

Pre-Impresos: ¿Cuál es la importancia del evento en la comunidad de educadores matemáticos?

WJ: La jornada Educador Matemático nos permite encontrarnos y socializar nuestro trabajo con la comunidad académica, para que sea juzgado, evaluado y mejorado. Además, también permite a los estudiantes conocer los proyectos de práctica que les podría interesar en el futuro, así como acopiar ideas y explorar posibilidades para su trabajo de grado

Además de darnos a conocer como departamento dentro de la universidad, también nos permite conocer la misma universidad. Así, en la jornada, hemos definido espacios para abordar distintos temas de interés coordinados por la jefatura del Departamento Matemáticas, por Bienestar Universitario y por la coordinación de la Licenciatura en Matemáticas. Por ejemplo, hemos tenido charlas sobre el Reglamento Estudiantil, sobre los nuevos decretos de ley, sobre la propuesta de reforma del Estatuto Académico, sobre el proceso de acreditación.

Pre-Impresos: ¿Cómo se organiza el evento, qué duración tiene, cada cuánto se realiza?

WJ: El evento dura dos o tres días depende el cronograma que se tenga a disposición y desde el inicio de cada semestre empezamos la organización; a hacer las invitaciones, los diseños de poster, la publicidad, etc., este proceso dura todo el semestre $y$, generalmente, el evento se ejecuta durante la semana número 12.

Pre-Impresos: ¿Qué proyecciones a corto, mediano y largo plazo se tienen con la JEM?

WJ: Nos estamos expandiendo poco a poco, ya tenemos la visita frecuente del Departamento de Matemáticas y Estadística de la Universidad Pedagógica y Tecnológica (UPTC) de Tunja, que nos viene acompañando todos los semestres y ya reconocen a la JEM como un evento académico importante en el cronograma de sus actividades, pero queremos que esto se replique con otras universidades, ya tratamos de impactar en otras universidades que tienen carreras afines acá en Bogotá y queremos hacerlo también a nivel nacional, esto a largo plazo, pues a corto plazo nuestra meta es la ejecución de la jornada de este semestre. 


\section{ACERCA DE LA SERIE PRE•IMPRESOS}

La serie Pre./mpresos Estudiantes es un proyecto de la Facultad de Ciencia y Tecnología (FCT) de la Universidad Pedagógica Nacional que divulga a través de la comunicación escrita la producción intelectual de los autores, destacando sus experiencias y reflexiones respecto de los temas inherentes a sus campos disciplinares específicos y su enseñanza. Por tanto, configura un espacio de visibilidad y reconocimiento público del trabajo de los maestros en formación y en ejercicio adscritos a la FCT.

La escritura en el ámbito de las ciencias y la tecnología

La comunicación es un aspecto fundamental de los procesos de cognición que construye relaciones de fuerza e identificación entre las personas y define el lugar de cada individuo en un grupo. Así, toda relación social se funda en el intercambio de ideas, pues cuando hablamos y escribimos también damos forma al mundo. Por tanto, la conformación de comunidades académicas tiene un carácter social y comunicativo, proceso en el que la palabra escrita contribuye a la socialización de las ideas; dado que, la comunicación de la ciencia se realiza en lengua natural.

\section{¿Qué es un preimpreso?}

Los Pre-impresos son una publicación previa que se utilizan en comunidades académicas para difundir el trabajo de sus miembros y contribuir a la formación de futuros investigadores, apoyando la cualificación de sus procesos escriturales.

\section{Origen}

Este proyecto editorial también constituye un espacio académico de formación y cualificación docente, que se inspiró en un trabajo similar que realiza el grupo Física y Cultura del Departamento Física de la FCT, con trabajos de profesores, desde principios de la década de 1990, con el fin de promover la circulación de las ideas de los profesores adscritos a este grupo de investigación.

\section{Objetivos}

Pre॰Impresos Estudiantes promueve el fortalecimiento de la actividad académica en dos dimensiones; como proceso de formación escritural de los futuros maestros de ciencias, matemática y tecnología, y como iniciativa editorial que se traduce en una publicación seriada que divulga la producción intelectual de los estudiantes de la FCT.
El carácter del proceso realizado y el acompañamiento escritural que se brinda desde el proyecto hacen de esta experiencia una actividad académica de formación docente, con proyección en la práctica pedagógica e investigativa que contribuye a:

- Apoyar los fines misionales de la Universidad de investigar, producir y difundir conocimiento profesional docente, educativo, pedagógico y didáctico, además de propiciar una interacción con la sociedad para aportar a la construcción de nación.

- Propiciar una mayor consciencia lingüística, al poner de relieve la relación entre ciencia y lenguaje en el proceso de construcción textual, que requiere el desarrollo de la capacidad discursiva y habilidades comunicativas.

- Fortalecer la comunidad académica de la Facultad, al visibilizar las líneas de trabajo de los grupos de investigación de las diferentes unidades académicas.

\section{Características}

Pre॰Impresos Estudiantes es un proyecto institucional de carácter extra curricular en el que pueden participar los estudiantes de los diferentes programas de la Facultad que quieran vincularse, ya sea, de manera individual o en grupo. El proceso de acompañamiento que se brinda exige compromiso y disciplina de los participantes, para la cualificación de su proceso escritural. Los temas a trabajar pueden cobijar una amplia gama de aspectos relacionados con las disciplinas — las ciencias, la matemática, la tecnología - y su enseñanza, así como, con la educación en general, ya sean reflexiones de carácter epistemológico y/o pedagógico, entre otras posibilidades.

Se puede participar con un amplio tipo de formatos de escritura, como por ejemplo: artículos, ponencias, módulos didácticos, cartillas, ensayos, crónicas, experiencias de aula, diarios, informes de investigación, por solo mencionar algunos. El proceso de elaboración, edición y publicación final de cada documento se ajusta al tiempo requerido por los autores para culminar esta labor. La publicación se hace en forma de cuadernillos monográficos en formato digital e impreso. La convocatoria es permanente. 


\section{Sobre el autor}

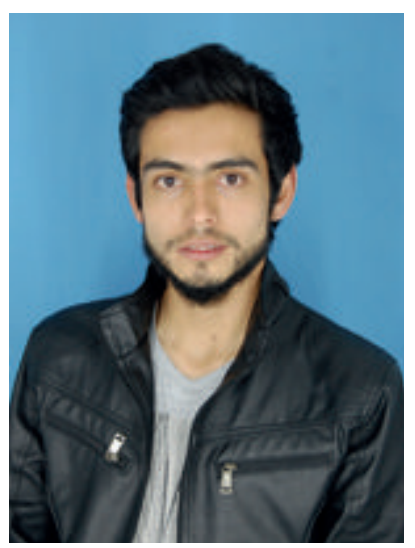

Licenciado en Física de la Universidad Pedagógica Nacional (2017), ha laborado como docente de física y matemáticas, le interesa la enseñanza de la física, un área convertida en el terror de los estudiantes de últimos grados de educación media. Reside en Mosquera, Cundinamarca, donde ejerce su profesión. Inició este año asumiendo un reto nuevo: enseñar matemáticas en primaria y, además, dirigir un club de astronomía, para mostrar a los estudiantes otra cara de la ciencia relacionada con la matemática.

Participó en el III Conversatorio sobre naturaleza del conocimiento científico y la formación de profesores de ciencias de la naturaleza (2016), organizado por la Universidad Distrital y el Departamento de Química de la Universidad Pedagógica Nacional, con la ponencia titulada "El tiempo y espacio relativista con estudiantes de grado séptimo", que fue fundamental para el desarrollo de su trabajo de grado "La enseñanza de la TER: reglas fijas y relojes con estudiantes de $7.0^{\circ}$. Fue representante estudiantil en los años 2016 y 2017 al Concejo del Departamento de Física de la universidad de la cual es egresado.

Cercano siempre a la filosofía, a la política y a la educación, se interesa por la filosofía de las ciencias que tiene un impacto en el ámbito educativo, estrechamente relacionado con la política.

\section{http://revistas.pedagogica.edu.co}

